$2^{69}$

NT Maine Aqucultural Espeumen Station, 12 th Annuad lepor 1896. pt. 2 

F. L. HARVEY

$\mathrm{S}$

69

.E2
ENT

A NEW GARDEN

SMYNTHURIP.

Sprey nutiturus allameneulata.

IPlate 


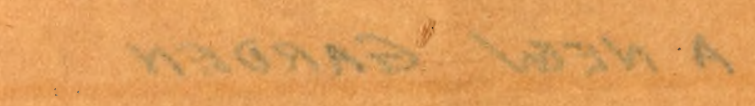$$
\cos 20
$$

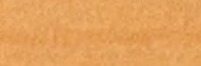

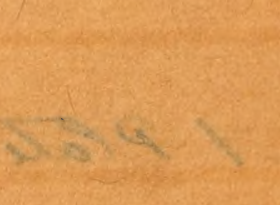

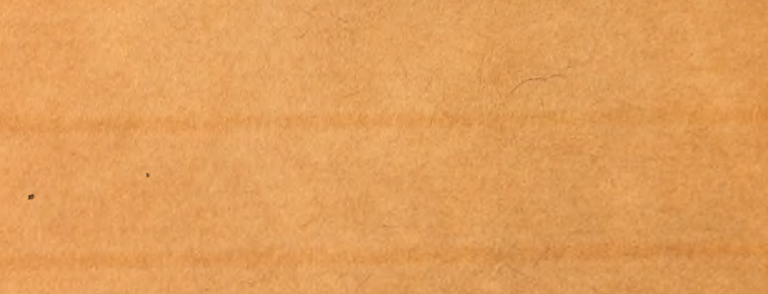


$12 T H A N$ RPT

MAINE AG EX ST $189 \%$ EPATII

NOTES ON INSECTS.

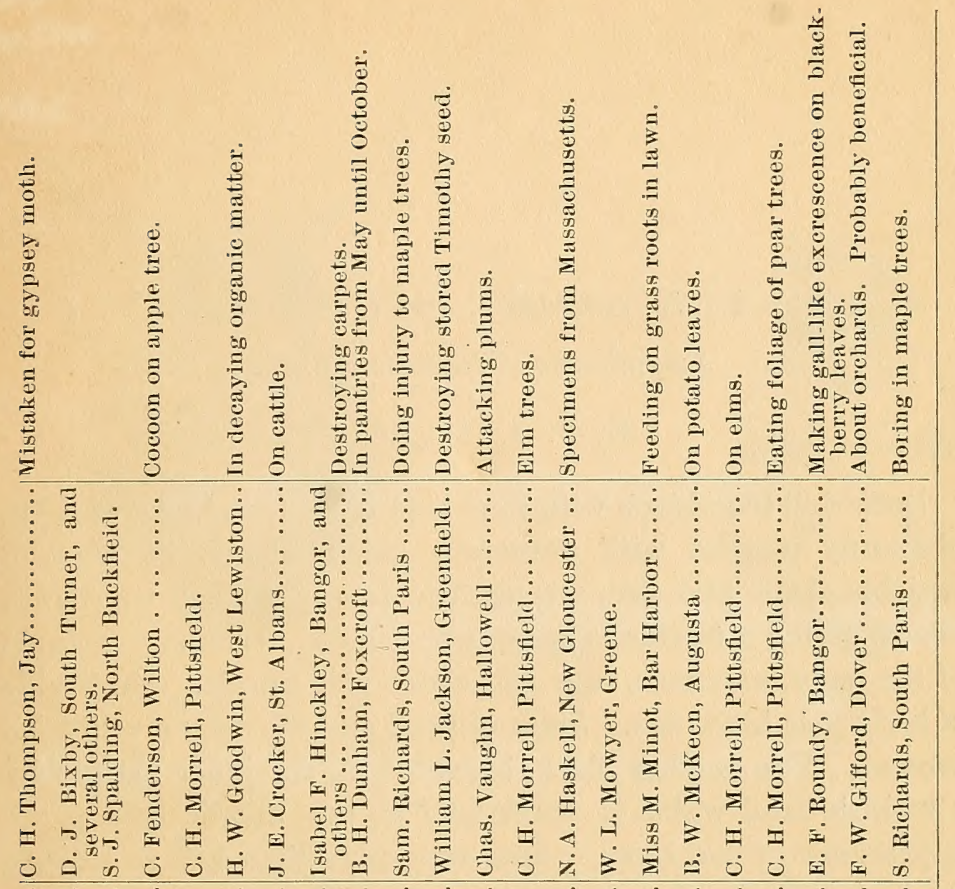

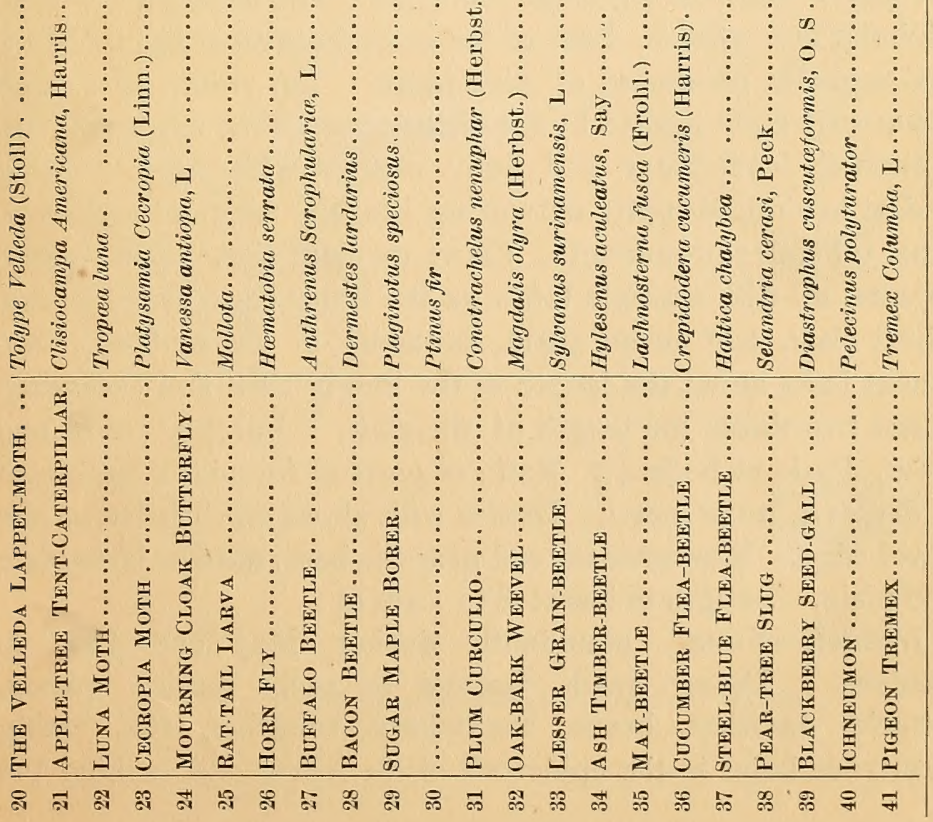




\section{A NEW GARDEN SMYNTHURID.}

Smynthurus albamaculata n. sp.

$$
\text { By F. L. Harvey. }
$$

Body dull blue-black with steel blue reflections in direct light, obscurely marked with numerous small whitish blotches of variable shape and size, arranged in poorly defined transverse bands, giving a marbled appearance. Hearl, terminal segments of the body, antennae, legs and elater pale purple. Underside of body pale brownish. Sides of head and the vertex yellowish brown. Eye patches black, bordered on the inner margin by a whitish band which is constricted in the middle giving the appearance of two spots. Antennae more than half as long as the body. Ratio of segments $I: 2 \frac{x}{2}: 3: 5$. The basal joint widest, globular and whitish. Base of the second segment light. Terminal segment composed of nine joints. (In young specimens apparently eight jointed by the coalescence of the two terminal). Antennae, legs, elater and body clothed with hairs. Body widest behind, abruptly narrowing into the terminal segments. Anal tubercles prominent. Claws medium size. The larger, $.031 \mathrm{~m}$. $\mathrm{m}$. with a single tooth on the inner edge near the end. Short claw, oI7 $\mathrm{m} \mathrm{m}$. plain, broadest in the middle. Two tenent hairs about the length of the longer claw and extending about two-thirds the length of the claw. Furcula short and stout. Ratio to body 4:7. Ratio of parts of furcula: manubrium 4 , dentes 4 , mucrones I. Dentes with about ten bristles on the lower edge. Mucrones curved near the base, narrow lanceolate and plain. Length of insect .8 to $1.4 \mathrm{~m} \mathrm{~m}$.

Habitat:-Found abundantly during May and June in gardens. Doing much damage to early garden plants. Attacks radishes, beans, cucumbers, squashes, etc., eating numerous holes in the epidermis of the leaves and sucking the 


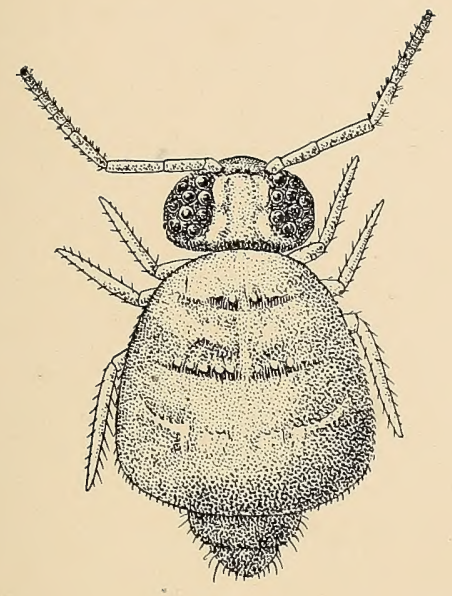

Fig. 1.

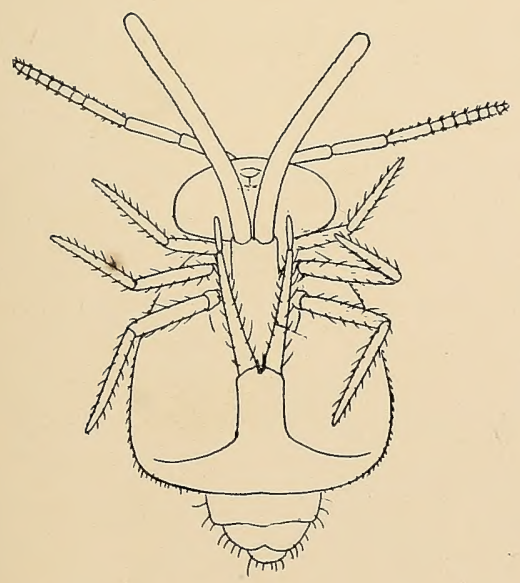

Fig. 2.

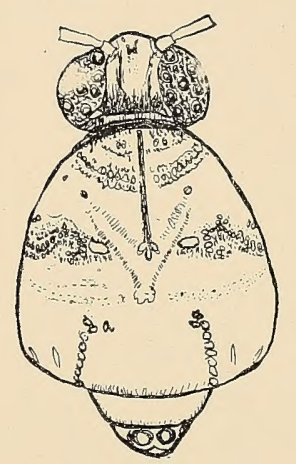

Fig. 3 .
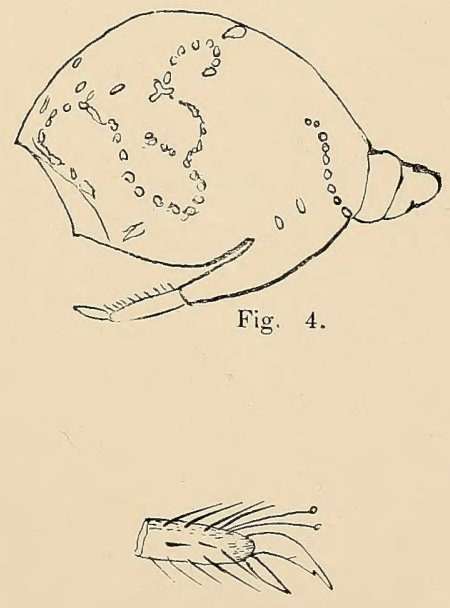

Fig. 5 .

SMYNTHURUS AlBaMACUlata, Harvey. 

juices until the leaves wither. Numerous specimens examined during the last five years. Orono, Me., F. L. Harvey.

Distinguishing characters:-This species has the same habits as Fitch's $S$, hortensis and is equally as injurious. For a long time we took it for that species. It has the dark body and lighter head, legs, antennae and elater of the above. It is, however, readily distinguished by the purple of the head, antennae, terminal segments of the body and elater, the obscure white markings on the body and especially by the nine joints to the terminal segment of the antennae. There being in $S$. hortensis six segment to the terminal joint, according to Fitch and McGillivray-but really seven if Fitch's figure is correct. The only species we know of having been found in America with nine joints to the terminal segment of the antennae is $S$. roseus, Packard, from which our species differs in the color of the body, size and habits.

Remarks:-The young of this species are lighter colored than the adults, appearing brownish to the naked eye and often show only eight joints to the terminal segments of the antennae. The older specimens acquire the blue black color and reflections. The marbled appearance of the body cannot be seen by the naked eye or a hand glass readily and the casual observer would say the body was plain, blackish. The whitish markings can be readily seen by magnifying 75 diameters. They appear as though they were under the skin and show through it. Alcohol and glycerine specimens show the markings plainly.

By careful examination of alcoholic specimens we found there was a median dorsal brownish stripe extending from the head half the length of the body and ending in a clover leaf white spot, There are three obscure transverse bands made up of white spots, giving the surface a mottled appearance. The anterior band from dorsal view shows two white spots each side the median line. The second stripe bears five oblong spots each side of the median line and lower on the sides an S shaped marking composed of a chain of white blotches. Still lower on the side and anterior to the first and sloping forward is another $\mathrm{S}$ formed by a chain of spots, the lower loop of the first S making the posterior loop of the second. See Fig. 4. 
Starting near the base of the manubrium and running obliquely up the side of the body and ending in the dorsal view is a stripe of oblong whitish spots. The white spot next to the dorsal end placed inward out of line. Fig. 3, a.

We have tried to show the arrangement of these markings in Figs. 3 and 4 .

Description of Figures:-Fig. I, drawn by Mr. J. H. Emerton from live specimens, shows well the form of the body and the obscure transverse bands. The drawing was made from live specimens. Fig. 2, drawn by Mr. Emerton, shows a ventral view of the same. Fig. 3, drawn by the writer, shows in detail the white markings as seen in alcoholic specimens, examined by high powers. No attempt is made to show more than the location of the markings. Fig. 4 , is a side view showing location of the spots. Fig. 5, shows structure of the foot.

Remedies:-We do not agree with Fitch that the work of the Smynthurids is entirely secondary, at least this species is capable of sucking the juices in some way without the aid of other insects. The above species was very abundant on cucumbers in my garden this season but we did not notice the Flea Beetle. Some times there would be more than a dozen on a single leaf. In a few days the leaves turned whitish and on examination the epidermis was found full of little pits. Rarely, if ever, was there a hole through the leaf. They attack the new, young plants, eating the seed leaves (cotyledons). The application of dirt, ashes, sulphur or pyrethrum while the dew is on will act as deterrents until the plants are larger when they appear to do but little damage. We searched for specimens June $25^{\text {th }}$, and found them very scarce. 

